$M^{a}$ José Bruno Aniorte

Arquitecta por la Escuela Técnica Superior de Arquitectura, Universidad

Politécnica de Madrid.

Especialista en

Arqueología de la

Arquitectura.

En curso de realización de tesis doctoral.

\title{
Martini-Made. Ferrater-Fisac Bajo el mismo concepto
}

\author{
Keywords: Ferrater, Martini, Fisac, Made, confluences
}

In 1959 Miguel Fisac was engaged to project and construct a new industrial building: the pharmaceutical laboratories "Made". One year earlier, Jaime Ferrater Ramoneda, a young Catalan architect settled in Madrid, completed in the same city a project for a new liquors manufacture building "Martini and Rossi". While Fisac reached the zenith of his professional career, Ferrater on the other hand, was at his beginnings with this project. Apparently without any connections between the two creators, both chose a similar approach to resolve the constructive needs requested by their clients, by providing a new, sincere and pragmatic vision. The article contains 10 comparative points, which aim to prove the conceptual similarities of these two magnificent examples of industrial architecture in Madrid.

\section{Introducción}

T as la guerra civil española, y ya superado el periodo de autarquía económica se inició la nueva etapa de desarrollismo, plasmada en un proceso de industrialización y modernización de decisivas consecuencias. Este proceso fue destacable de forma especial en Madrid a raíz de una politica aperturista en lo económico como consecuencia, entre otras cosas, del acuerdo económico y militar firmado con Estados Unidos en 1953. En virtud de la nueva politica se afianzaron también los otros núcleos industriales importantes anteriores a la Guerra Civil, como eran el País Vasco, Asturias, Barcelona o Valencia.

En el caso de Madrid, un cierto número de empresas, tanto españolas como extranjeras, decidieron instalarse en el cinturón periférico de la ciudad, siguiendo con ello las directrices dadas a tal efecto en el Plan General de Ordenación Urbana de Madrid, de fecha 1 de Marzo de 1946 (Del Río Lafuente, 1984: 81-83). En él se destinaba el sur para la ubicación de industria pesada, con ejemplos como Barreiros, Boetticher y Navarro, Marconi y Manufacturas Metálicas Madrileñas, entre otras, y el norte y este para la industria ligera, como las farmacéuticas Jorba, Farmabión, Made y Profidén, o alimentarias como Clesa y Martini y Rossi. Así pues, estarian entre estas últimas las dos ya citadas que nos ocupan.

La incipiente corriente aperturista provocará también la incorporación de nuevas formas y materiales, influenciados por las tendencias racionalistas e innovadoras imperantes en el resto de Europa y Estados Unidos, cuyo recorrido había sido iniciado varios años antes.

Las dos obras seleccionadas en este artículo fueron concebidas en los albores de esta incursión de aire fresco, y ambas presentan una serie de coincidencias destacables que resumiremos en diez puntos. Diez puntos correspondientes a los siguientes apartados $\mathrm{y}$ en los que convergen los dos proyectos, y de los cuales nueve son los más esenciales y de carácter conceptual, mientras que en el décimo punto se destaca su privilegiada condición de edificios supervivientes.

\section{El hombre y la máquina}

En un edificio industrial surgen de forma natural dos zonas diferenciadas: una con predominio de la máquina y otra para el trabajo del hombre. ${ }^{1}$ Torroja se refirió a ello en el planteamiento de su Instituto para la Construcción y el Cemento: el pensamiento y la obra, el hombre y la máquina, que podian trabajar de forma conjunta pero sin interferirse (Echegaray y Barbero 1953). Tanto en la fábrica de Martini como en los laboratorios Made esta definición de espacios se encuentra claramente diferenciada de una forma no habitual hasta entonces.

En la fábrica de Martini, Jaime Ferrater proyectó un primer edificio, compacto y de tres plantas, destinado a oficinas, servicios sociales del personal, el club Martini, y una futura vivienda para el director. Sería el correspondiente de forma principal al trabajo y actividades del hombre. Un segundo edificio compuesto por varios volúmenes albergaba la factoria propiamente dicha. La separación conceptual de estos dos espacios queda plasmada en los planos de los dos edificios, los cuales dibuja en láminas independientes en el proyecto inicial del año 1958. No fue hasta el año 61 cuando, por razones urbanísticas, se ve obligado a modificar la ubicación del edificio de oficinas, cambiando su orientación y situando su fachada principal paralela a la fachada de la fábrica, a la vez que conectán- 


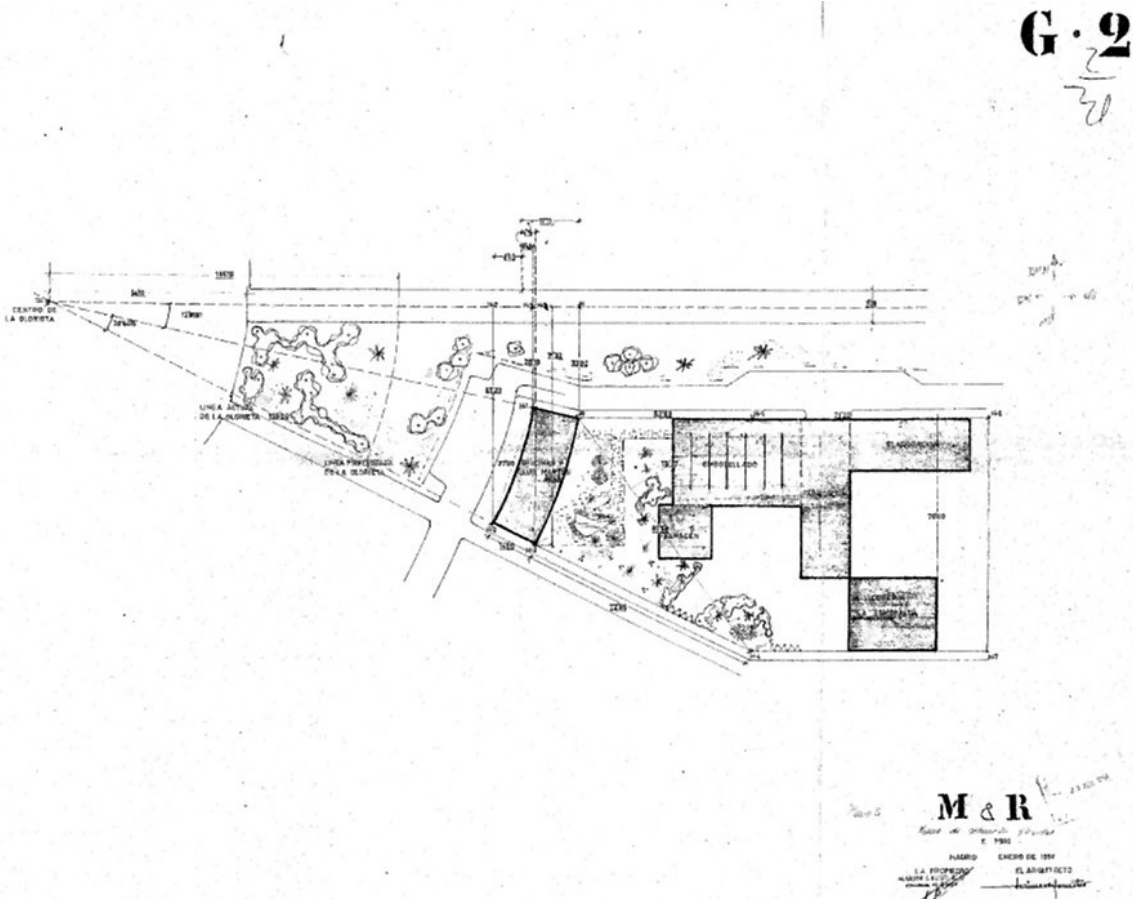

dolos entre sí mediante un paso cubierto y cerrado que sirve, a su vez, de entrada principal. Cabe destacar el carácter corporativo que el club Martini representaba, dotándolo de un acceso independiente y directo desde la calle, y cuidando a su vez los aspectos estéticos ya que el club constituia la sede de las relaciones sociales de la firma (Figura 1).

En el caso de los laboratorios Made, Miguel Fisac recurre a la misma idea de separación de espacios entre el estudio teórico de los problemas (el hombre) y los ensayos o experiencias que las confirmen (la máquina), el pensamiento y la obra según la terminología de Torroja, destinando un pabellón, situado al norte, para oficinas, despachos y sala de cálculo, y el resto de edificios, en la cara sur, destinados a la producción. El edificio de oficinas quedaría conectado por la nave de fabricación con el resto de volúmenes a través de un pasadizo aéreo, dos "paquetes", comunicados entre sí de una manera, aunque no directa, sí fácil, según el propio Fisac (Cánovas, 1997: 131) Para facilitar el acceso práctico de todos los pabellones, éstos se interconectan además, en la planta sótano (Figura 2).

Al igual que Ferrater con el club Martini, Fisac dota al edificio de oficinas de un acceso directo y trata con sumo esmero el hall principal, lugar de espera de posibles clientes, no escatimando en la calidad de los acabados.

\section{Cada volumen, su actividad}

Con cierta analogía maquinista, tanto Ferrater como Fisac concibieron sus fábricas como un conjunto de piezas con carácter propio, pero conectadas entre sí a modo de mecanismos.

La fábrica de Martini consta de cuatro partes bien diferenciadas, sin contar con el edificio de oficinas: una primera nave donde se ubica la sala de embotellado en planta baja. Sobre ella el almacén de envases vacíos, un taller de carpintería, y otro de pintura y publicidad. Un segundo pabellón de elaboración del vermut, con almacenes para las materias primas. En este segundo pabellón concentra,
Figura 1. Plano de situación. Proyecto del año 1958. Archivo General de la Administración (A.G.A.) (Expediente Martini Rossi 1958)
Figura 2. Plano de planta baja. Al norte se aprecia el pabellón de oficinas independiente del resto de pabellones. (Cánovas, 1997: 130)

Figura 3. Alzado-sección oeste. Proyecto original. Archivo General de la Administración (A.G.A). (Expediente Made 1961)

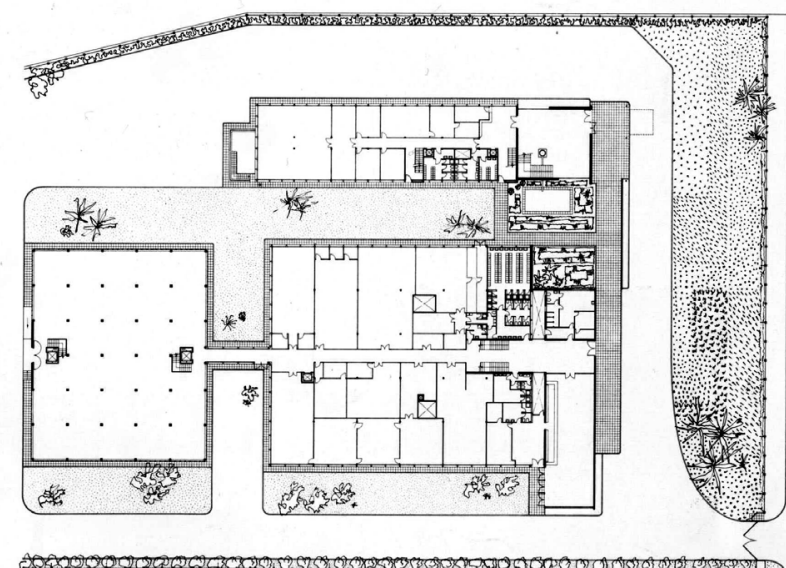

म

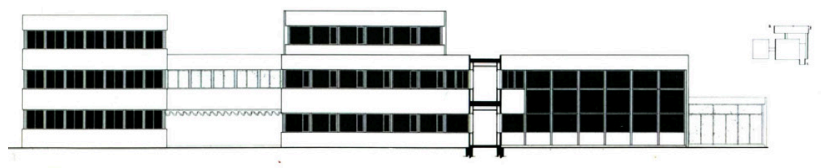




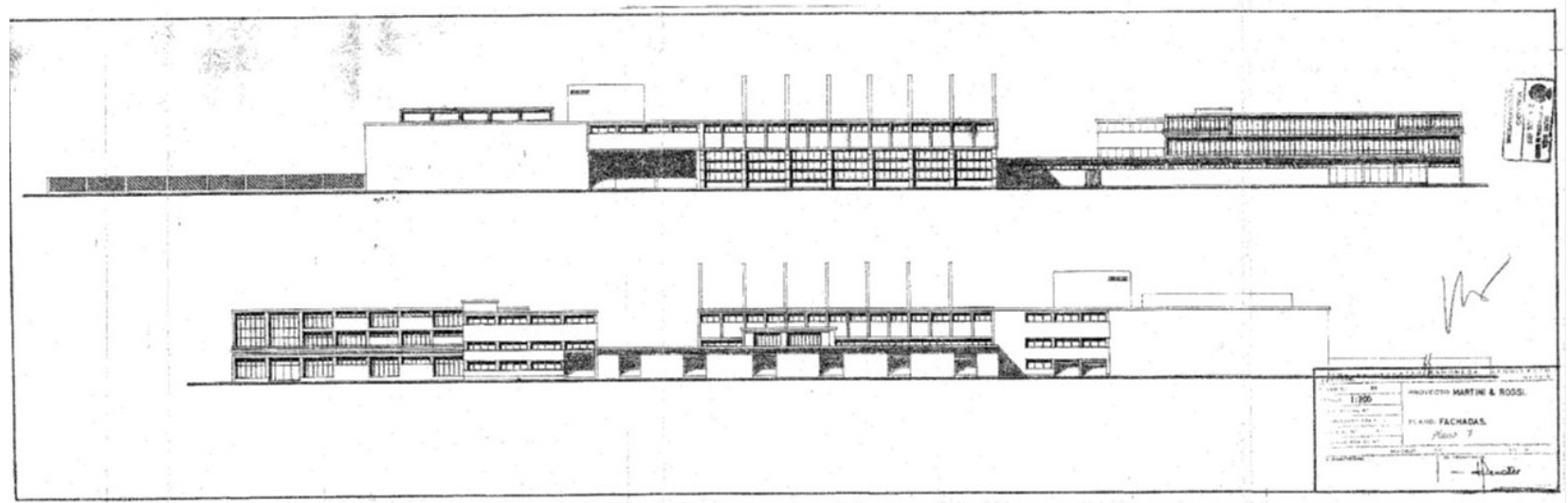

Figura 4. Alzado general. Fachada sur. Año 1961. Archivo General de la Administración (A.G.A.). (Expediente Martini Rossi 1958) además, todos los elementos de comunicación vertical como montacargas, escaleras y una cinta transportadora de rodillos. En el tercero, se alojan las tinas para el macerado, que, a su vez, forman parte de la estructura. $\mathrm{Y}$ un cuarto volumen, pequeño y adosado a la cara sur de la nave de embotellado, que sirve de almacén. En el proyecto del año 58, y dentro de la misma parcela, un tercer edificio aparece en el extremo sureste del conjunto de producción de vermut: es la fábrica de licores "La Esmeralda": “... perteneciente a la misma entidad, pero que por causas de su destinación se sitúa independiente totalmente de la fábrica de vermut, sin comunicación alguna con ella más que por el exterior..." según describe Ferrater en la memoria. Sin embargo, en los planos que visa en 1961, aparece descrita como licorería, adosada en la cara sur al edificio de oficinas y con comunicación directa con él.

En su proyecto, Jaime Ferrater define y muestra con toda claridad cada uno de los volúmenes que componen la totalidad de la fábrica, reconociéndose cada uno de ellos, tanto en planta como en alzado, donde dota de un tratamiento distinto a cada una de las fachadas que componen dichos alzados (Figura 4).

En el caso de Fisac con los laboratorios Made, al contrario de la propuesta de un contenedor único como solución a su anterior proyecto para los laboratorios Farmabión, la distinción de volúmenes se enfatiza, se hace más evidente, y concibe el proyecto como "... varios edificios independientes enlazados con pasadizos subterráneos o elevados." (Expediente Made 1961), sugiriéndose de nuevo la analogía de organismo mecánico.

Cada uno de estos edificios está tratado de manera particular, dependiendo de la función encomendada. Asi, en la zona norte se sitúa el pabellón de oficinas y despachos, es decir, el edificio representativo de la firma que en este caso se dispone perpendicular a la vía de acceso. Un segundo pabellón conectado con el primero por un enlace subterráneo y otro aéreo en la segunda planta, es el destinado a nave de fabricación, disponiendo en su interior de una comunicación central abierta en la totalidad de las plantas, a modo de patio-corredor longitudinal. En la tercera planta de este pabellón se sitúan los laboratorios de investigación. Un tercer edificio, que sirve como depósito de materias primas y almacén de productos terminados, se conecta en prolongación al edificio de fabricación en todas sus plantas a través de galerías de comunicación. Y aún se contó con una cuarta y última construcción inicial, destinada a cafetería, vestuarios y aseos, que se adosó al edificio de fabricación en su cara este (Figura 3).

\section{Modulaciones diferentes en cada volumen}

Tanto Fisac como Ferrater, al concebir sus respectivos proyectos como volúmenes independientes, adaptaron de manera consecuente sus respectivas estructuras. En el caso de Ferrater, la estructura la resuelve a base de pórticos y en el de Fisac con retículas modulares, adoptando en ambos un lenguaje claramente racionalista conforme a los cánones imperantes en el resto de Europa.

Para la fábrica de Martini, Jaime Ferrater adopta el sistema del pórtico de hormigón armado como elemento estructural en el edificio de oficinas y en el de fabricación y depósito de materias primas, ambos con pórticos dispuestos transversalmente a la mayor longitud del edificio. En el edificio de oficinas, dos hileras de pórticos de $5,80 \mathrm{~m}$ con una separación entre ellos de 5,20m. En el de elaboración, las dos hileras de pórticos se amplían a 7,50m de luz, con separación entre ellos de 5,20m, al igual que en el almacén. Sin embargo, en la fábrica de licores se decanta por una retícula menor, de 4,43 x 4,43m. En todos ellos utiliza forjado tipo autárquico excepto en la nave de 


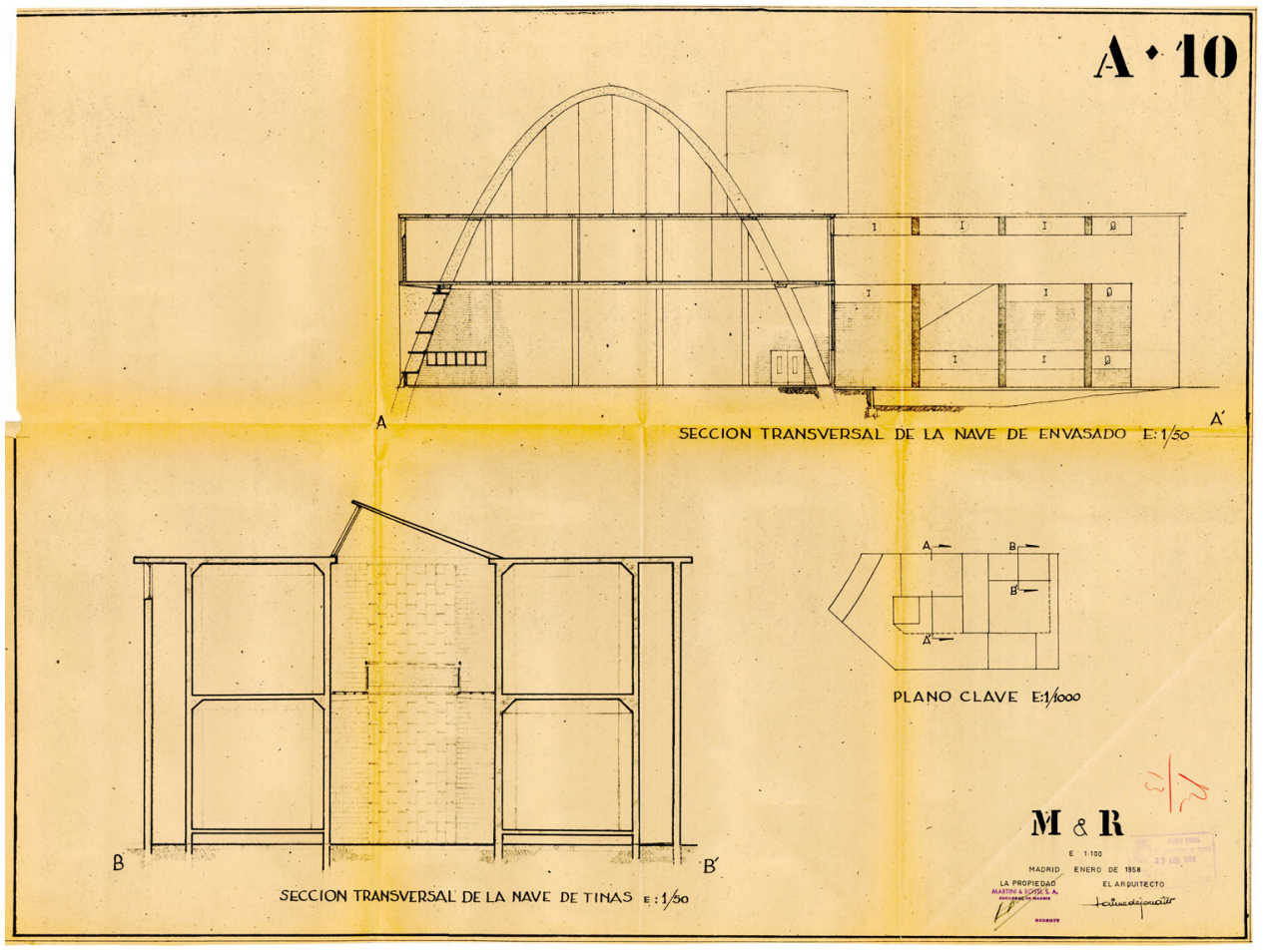

elaboración, que será sustituido por una losa maciza de hormigón armado con el fin de poder soportar maquinaria pesada.

Sin duda alguna, sus mayores logros los consigue en la nave de embotellado y en la de tinas. Dos condicionantes marcaron la forma estructural de la nave de embotellado: la necesidad de cubrir un gran espacio diáfano, y la posibilidad de futuras ampliaciones. En la memoria del proyecto, redactado en Diciem- bre de 1957, Ferrater lo describe de la siguiente manera:

“... la necesidad de prever ampliaciones dicta la condición de cubrir la nave de envasado sin pilares, objetivo que se logra mediante la aplicación de formas especificamente resistentes cual es el arco parabólico rebajado triplemente empotrado ${ }^{2}$ que permite alcanzar una gran esbeltez y por lo tanto la mayor economía posible".

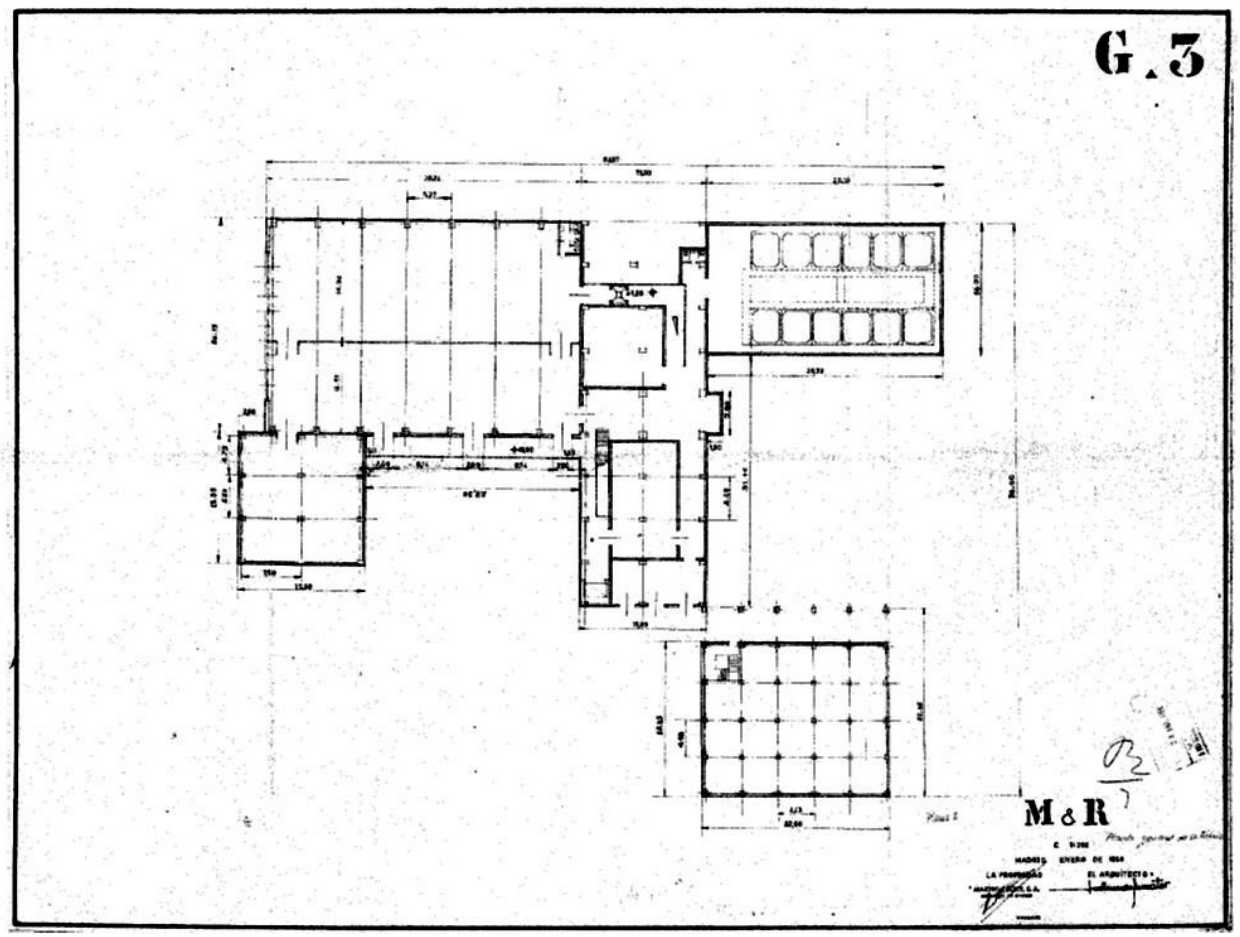

Figura 6. Plano general. Planta baja. Año 1961. Archivo General de la Administración (A.G.A.).(Expediente Martini Rossi 1958) Martini Rossi 1958) 
Figura 7. Plano de planta primera en el que se aprecia claramente el módulo estructural de cada pabellón. (Cánovas, 1997: 133)
Figura 8. Vista general y plantas baja y primera (giradas $180^{\circ}$ respecto a publicación original). Informes de la construcción, 169, p.35, Abril 1965.
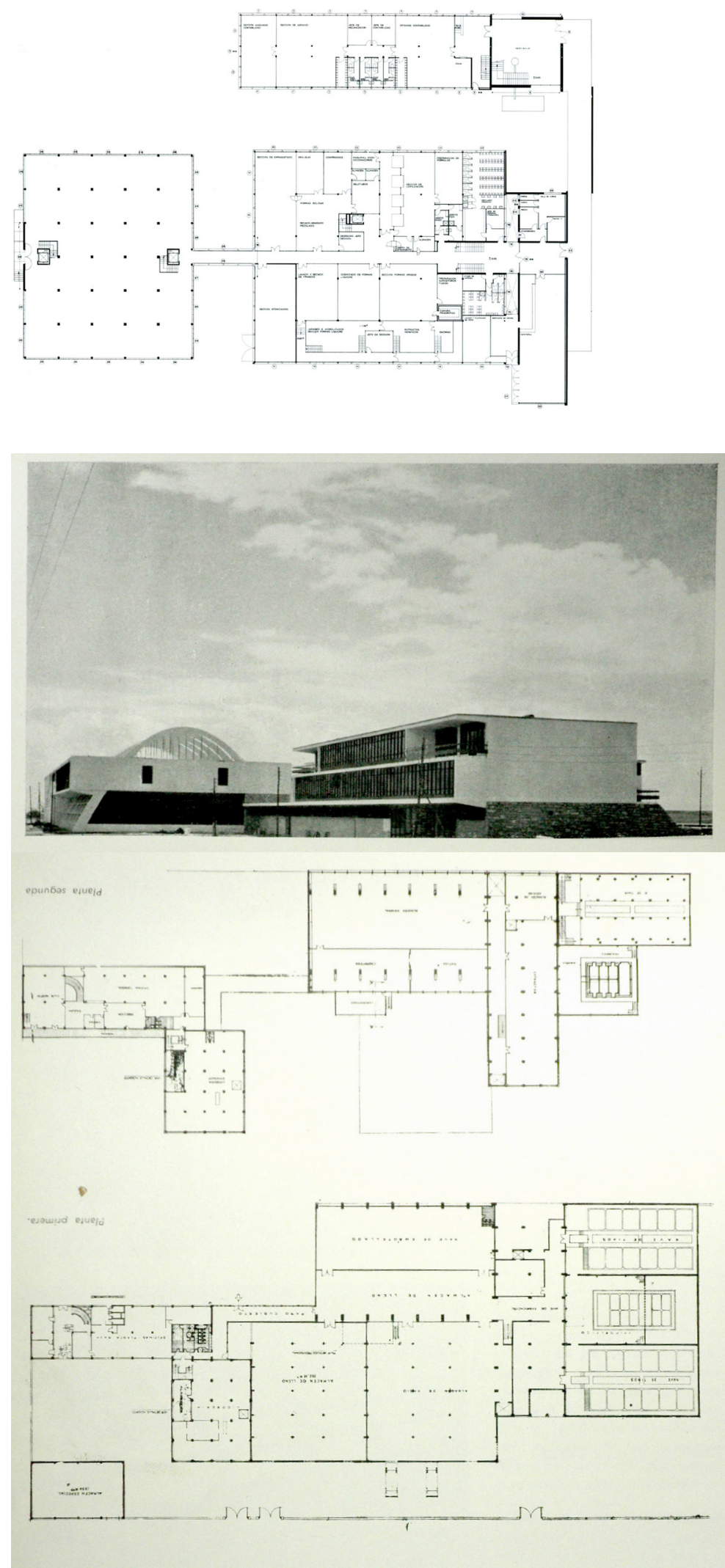

Bajo ellos suspende, por medio de tensores regulables, la cubierta del almacén de envases vacíos y su forjado, techo a su vez de la nave de envasado. Con un sencillo sistema de juntas, y una parte del forjado en voladi$\mathrm{zo}$, consigue de forma ingeniosa y original la posibilidad de permitir el equilibrio de esfuerzos, en casos extremos de sobrecarga, con la regulación de un solo tensor. En la nave de envasado, por tanto, obtiene una luz libre de 26 metros de anchura y $39 \mathrm{~m}$ de largo con una sucesión de siete arcos parabólicos cada 5,27 metros a ejes. Se completa con una altura libre de 5 metros (Figura 5).

$\mathrm{El}$ otro de sus logros estructurales lo realizó en la nave de tinas. Con el fin de ahorrar en material, aprovechó los espesores de las paredes necesarios para soportar los empujes horizontales ocasionados por el líquido, como soporte de la cubierta. Para facilitar la limpieza interior de los depósitos, achaflana las aristas que, junto con una armadura adecuada, hacen además las veces de pilares. Estos tienen la finalidad de sustentar el tramo de cubierta en voladizo que sobresale a ambos lados de cada hilera de tinas. La nave en sí consta de dos crujías de seis tinas cada una de $6 \mathrm{~m}$ de ancho, con un espacio abierto intermedio de 3,60 $\mathrm{m}$ y galerias de acceso al segundo piso o nivel de tinas, a modo de patio-corredor central (Figura 6).

En el caso de los Laboratorios Made, Miguel Fisac optó por un sistema estructural a modo de retícula. Cada edificio dispondrá también de un módulo distinto a fin de resaltar y adaptarse el carácter independiente de cada uno de ellos. Así en el pabellón de oficinas utiliza el módulo de $6,00 \mathrm{~m}$ con el otro lado algo menor, con un pasillo central de 2,00 $\mathrm{m}$ de anchura, por el que da acceso a todas las dependencias. En cambio, en la nave de fabricación, eleva el módulo a 7,00 x $7,00 \mathrm{~m}$. En este edificio dispone también de un pasillo-corredor en el centro, pero no varía el ritmo de la estructura, sino que lo inserta con holgura entre dos líneas de pilares. En cuanto al depósito de materias primas, opta por un módulo de 5,60 x 5,60 m en un espacio abierto, sin compartimentación. En todos ellos, la estructura está formada por un forjado continuo de placas aligeradas de hormigón armado sobre soportes de acero laminado.

A pesar de la composición interna diferente de cada uno de los volúmenes, éstos se componen entre sí de forma armónica consiguiendo un notable equilibrio en todo su conjunto (Figura 7). 


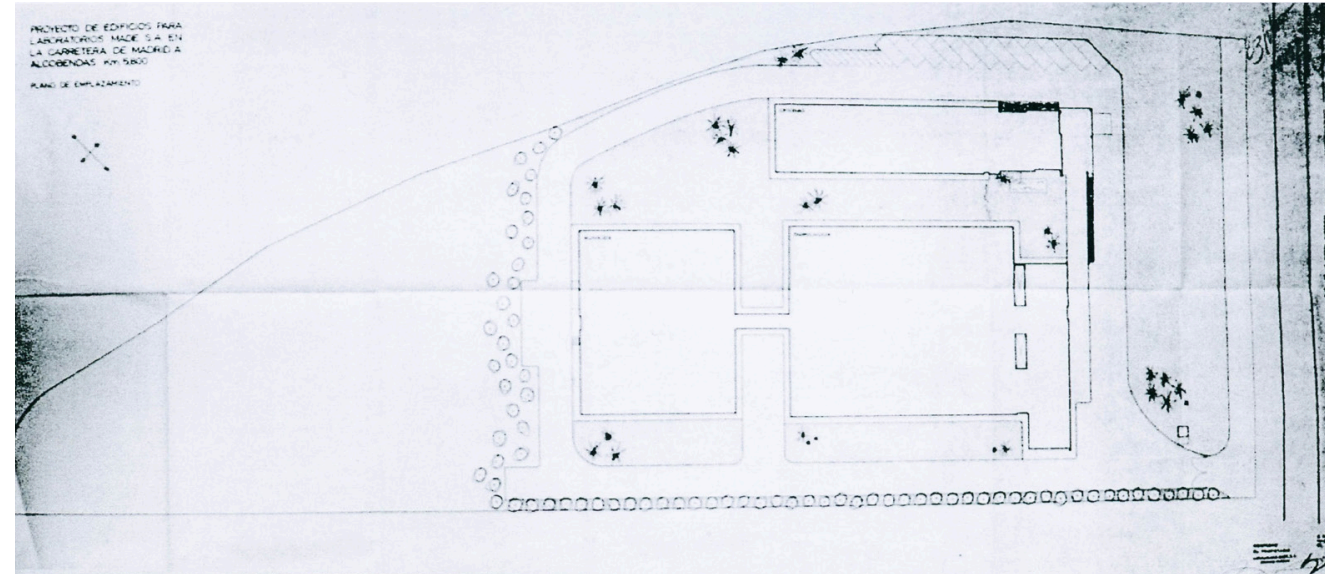

\section{Susceptibles de ser ampliados}

Uno de los requisitos que los clientes demandaron en cada uno de los dos proyectos a estudio fue el de la posibilidad de ser ampliados en un futuro, hecho que se llevó a cabo en ambos en varias ocasiones.

En el caso de la fábrica de Martini, dicho requisito condicionó de manera sustancial la forma de abordar la estructura en la nave de embotellado, aunque no solo esta nave vio ampliado su espacio, sino casi la totalidad de la fábrica. En Diciembre de 1961, Jaime Ferrater visó unos planos donde las partes ampliadas son: instalaciones de la licorería con nuevos alambiques, el almacén (de vacío) donde deja de ser un elemento anecdótico para convertirse en un volumen de gran presencia, un pequeño laboratorio ubicado sobre el almacén de vacío y adosado a la nave de embotellado, y una nave de frigoríficos. En Julio de 1965 visó un nuevo documento de ampliación donde aparece, esta vez sí, la prolongación de la nave de embotellado con tres nuevos arcos idénticos a los construidos, prolongación que se realiza hacia el edificio de oficinas. Además, construyó otra nave de envasado adosada a la anterior, hasta encontrarse con la licorería, y amplió la nave frigorífica rematándola al sur con una segunda nave de tinas de iguales dimensiones que la primera. Así acaba resultando un edificio más compacto, en el que todos los elementos se conectan entre sí, con un hilo de comunicación interna entre ellos. Ya en los planos de cimentación del almacén de vacío, fechados en Julio de 1961, dejó especificados unos anclajes para futuras ampliaciones (A.G.A. caja $n^{\circ} 2.190$ ) (Figura 8).

Miguel Fisac recurrió a una estrategia similar de ampliación con sus laboratorios Made. Al tratarse de un solar rectangular de grandes dimensiones, en vez de centrar inicialmente el edificio en la parcela, optó por ubicar los distintos pabellones en el tramo más cercano a la autovía Madrid-Burgos, reservando el lado oeste para futuras ampliaciones. De hecho, en la memoria del proyecto dice textualmente:
Figura 9: Plano de situación con solar completo. Proyecto original. Archivo General de la Administración (A.G.A.). (Expediente Made 1961)

Figura 10. Fotografía aérea de Google Earth, consultada en Internet el 13 de Abril de 2017.

Figura 11. Fotografía de vista general. Año 1963. (Cánovas, 1997:131)
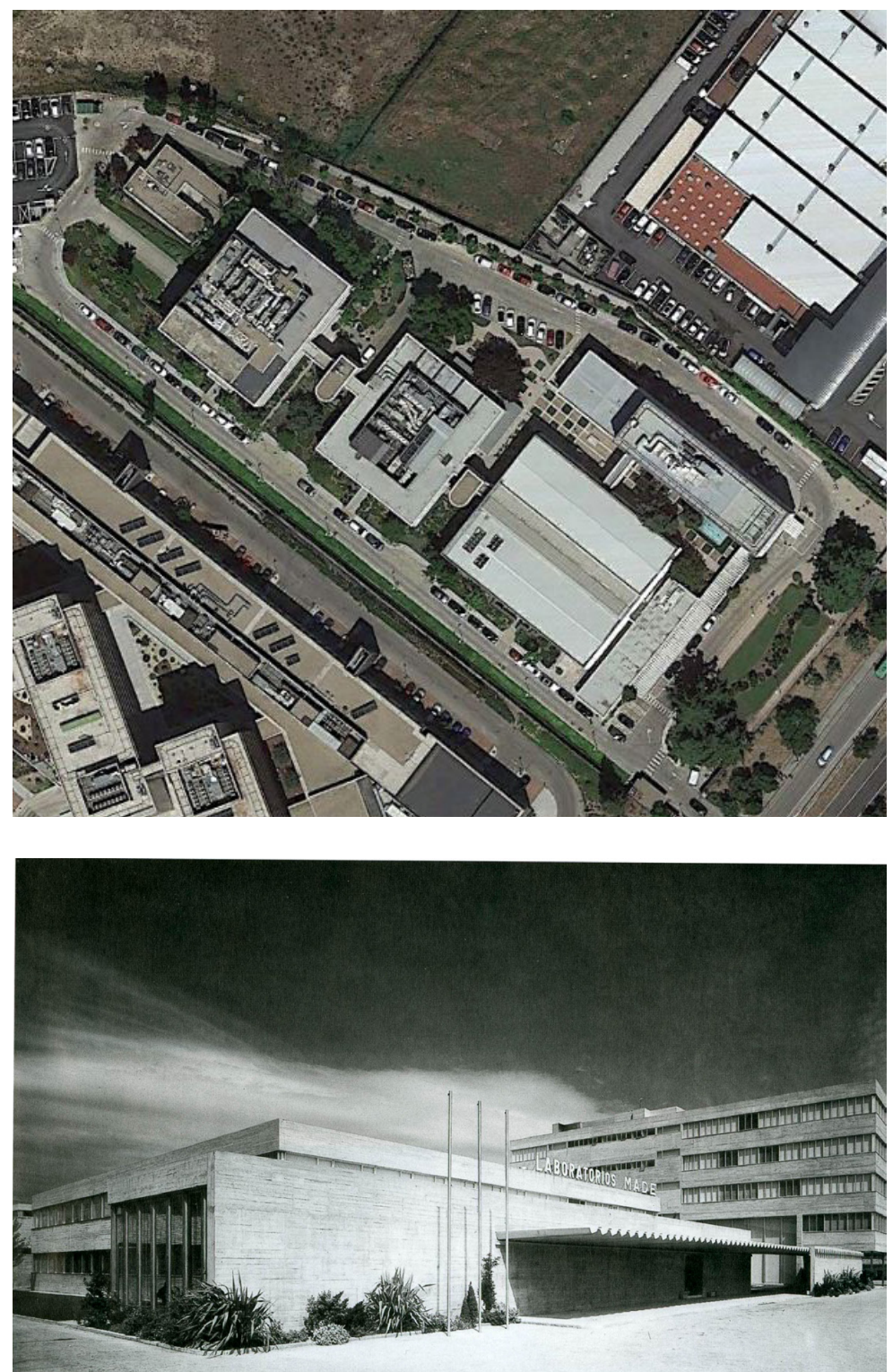
Figura 12. Fotografía de la escalera de traclub Martini. Informes de la Construcción, $\mathrm{n}^{\circ}$ 169, pp.35-45, Abril 1965.

Figura 13. Fotografía de la escalera de tramo recto hacia el altillo del club. Informes de la construcción, $\mathrm{n}^{\circ}$ 169, pp.35-45, Abril 1965. mo curvo de acceso al

Una galería subterránea enlaza toda la zona de planta primera de la nave de fabricación y se enlazará con la caldera de vapor, instalaciones eléctricas, etc., que se construirán posteriormente, en la parte oeste del conjunto. (Expediente Made, 1961) (Figura 9)

Fue en 1963 cuando el conjunto se amplió, dotándolo de un nuevo pabellón idéntico al depósito de materias primas, a continuación de éste en su lado a poniente, conectándolo mediante una galería y colmatando, de esta manera, la ocupación en planta del solar. En ese mismo año se intervino además en el edificio de oficinas, aumentando su altura original en dos nuevas plantas, con lo que acaba elevándose a cinco. Con ello se intensificó el carácter vertical con respecto a los demás volúmenes, y el impacto visual desde la carretera, marcando un hito publicitario para la firma. Actualmente ha perdido ese carácter debido a las numerosas edificaciones en altura construidas en los alrededores (Figura 10).
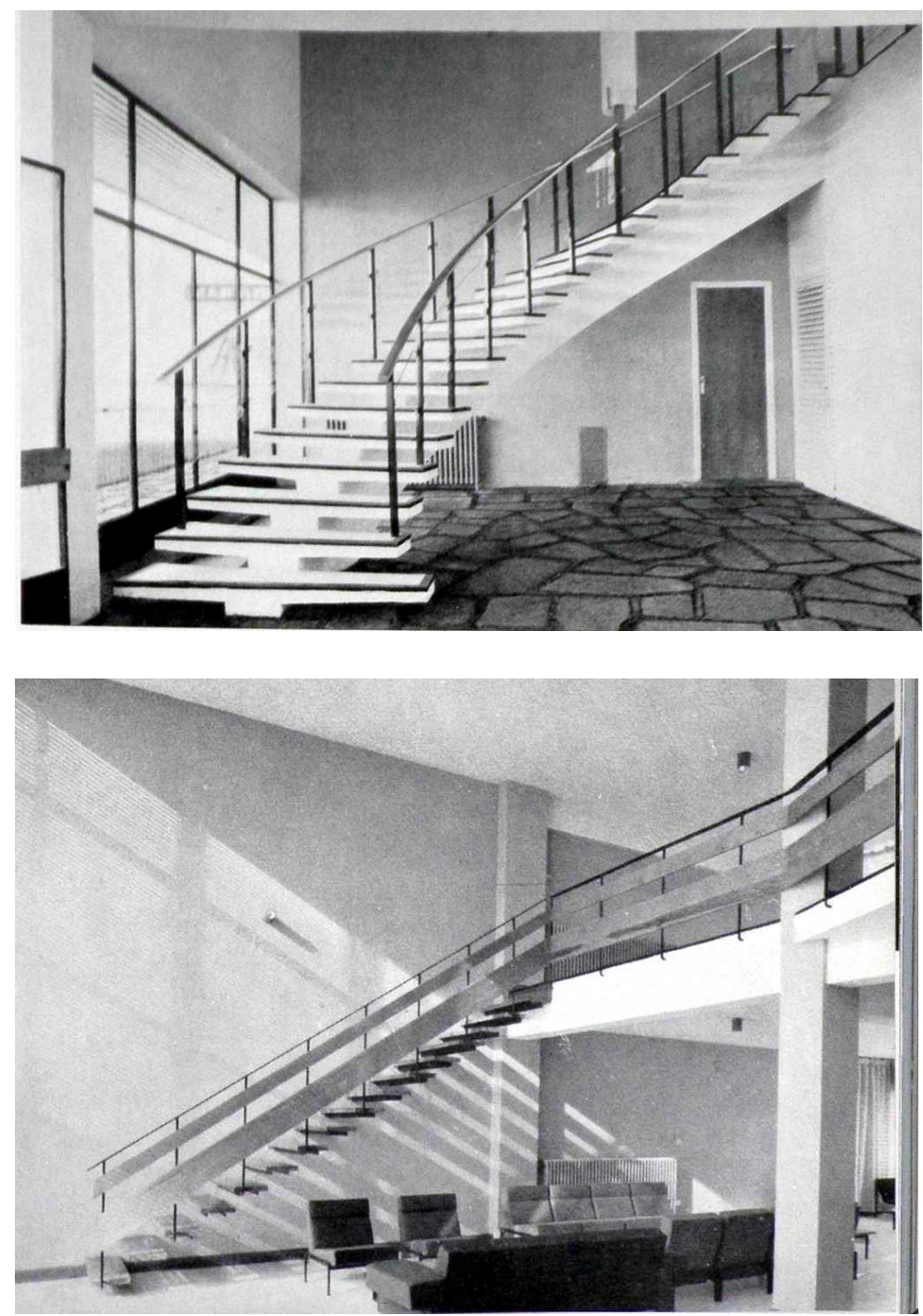

\section{Fachadas innovadoras}

Hacia finales de los años cincuenta del siglo XX España comenzó a resurgir del aislamiento en que había permanecido tras la guerra. Nuevos materiales habian surgido fuera de nuestras fronteras y comenzaban a ser utilizados con gran profusión. Sin embargo, costó trabajo incorporar esos nuevos materiales a la arquitectura española por falta de experiencia, escasez económica, y quizá, alguna reticencia. Pese a lo anterior, Ferrater incorporó como cerramiento en su proyecto para la fábrica de Martini un material novedoso como alternativa al tradicional ladrillo: el Durisol. Las placas prefabricadas de cemento y virutas de madera, de patente suiza, estaban conformando en esos momentos el mapa de la arquitectura industrial en el centro de Europa ( Bauen in Stahl, 1962). Ferrater no quiso quedarse atrás. Para ello especificó en la memoria del proyecto que los muros de cierre del edificio de oficinas "...se efectuarán en durisol armado con hormigón, con un espesor de $15 \mathrm{~cm}$...". Para la nave de elaboración prevé los muros exteriores con el mismo tipo de placas "durisol" apoyadas en la parte externa de la estructura. En la nave de tinas, no solo previó utilizar dichas placas en los muros de cerramiento, a los que aumenta a $25 \mathrm{~cm}$ de espesor con fines aislantes, sino que para la cubierta también las proyectó como elementos de forjado. Para la fábrica de licores, el sistema de cerramiento se diseño idéntico al de la nave de elaboración. Sin embargo, ese espíritu innovador se verá truncado a la hora de la puesta en obra, donde, finalmente, tuvo que optar por el sistema tradicional. ${ }^{3}$

Y respecto a Made:

A comienzos de 1959, este proyecto era el primero que realizaba con la intención de considerar al hormigón como el material más idóneo en nuestro tiempo para construir. Fue el primero en Madrid que se terminó en hormigón visto.

Con esta cita de Miguel Fisac recogida en la monografia de Francisco Arqués (1996: 150) podemos comprender la decisión y apuesta de su autor por la rotundidad plástica y visual del hormigón en los laboratorios Made. Después de años de búsqueda e investigación en nuevos materiales, llega a la determinación de que el hormigón es el material óptimo, por su plasticidad, para su uso en acabados exteriores. Al contrario de los elementos cerámicos que condicionan, por sus dimensiones, la composición de los alzados, con el hormigón todo es posible. Incluso las texturas de los 


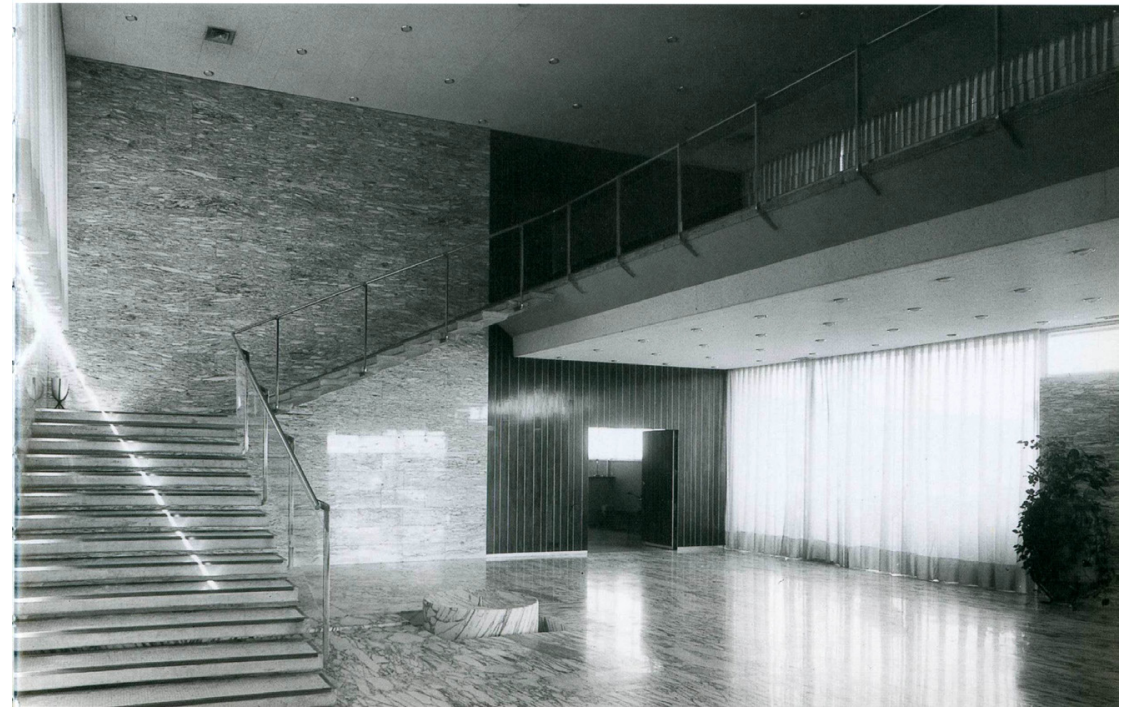

acabados pueden variar dependiendo de los encofrados utilizados. Con ese concepto, Fisac adoptó el hormigón como elemento clave en su nueva obra, transmitiendo una inusitada sinceridad al decidir dejar las fachadas con el color, rugosidad y textura propia de dicho material. Como él mismo indicó procuró un resultado "sin enmascaramientos" y con el presumible orgullo de la honestidad que transmitiria su obra (Fisac 1966: 21) (Figura 11).

\section{La escalera como simbolo}

Aunque algunas escaleras del ámbito industrial han sido tratadas como un simple trámite de comunicación entre dos plantas, otras, sin embargo, han sido proyectadas como elementos dotados de mayor dignidad y merecedores de especial atención. Las escaleras diseñadas en nuestras dos obras per- tenecen a este segundo grupo. Sin dejar de olvidar el carácter fabril de los dos edificios, tanto Ferrater como Fisac, mostraron una gran sensibilidad al prestar especial atención a este elemento singular.

En el edificio de oficinas de la fábrica de Martini, y más concretamente, en el club Martini, Jaime Ferrater optó por dar un carácter protagonista a la escalera, diseñándola curva y exenta en su primer tramo, con peldaños ligeros apoyados sobre una viga central, lo que permite, prácticamente sin obstáculos, el paso de la luz. Este elemento da acceso a una primera planta donde se ubica el club, con un hall a doble altura, dotado de un altillo al que se accede por un segundo tramo de escalera, esta vez recto y con peldaños de madera noble, volados y empotrados (Figuras 12 y 13).

Para los laboratorios Made, Miguel Fisac volvió a mostrar su maestría y habilidad
Figura 14. Fotografia del hall del pabellón de oficinas con la escalera volada. (Cánovas, 1997: 135)
Figura 15. Fotografia de nave de tinas de Martini, de la revista Arquitectura, $\mathrm{n}^{\circ}$ 55, Julio de 1963, p.6.

Figura 16. Escaleras de la nave de fabricación de Made, iluminadas con luz cenital. (Cánovas, 1997:135)
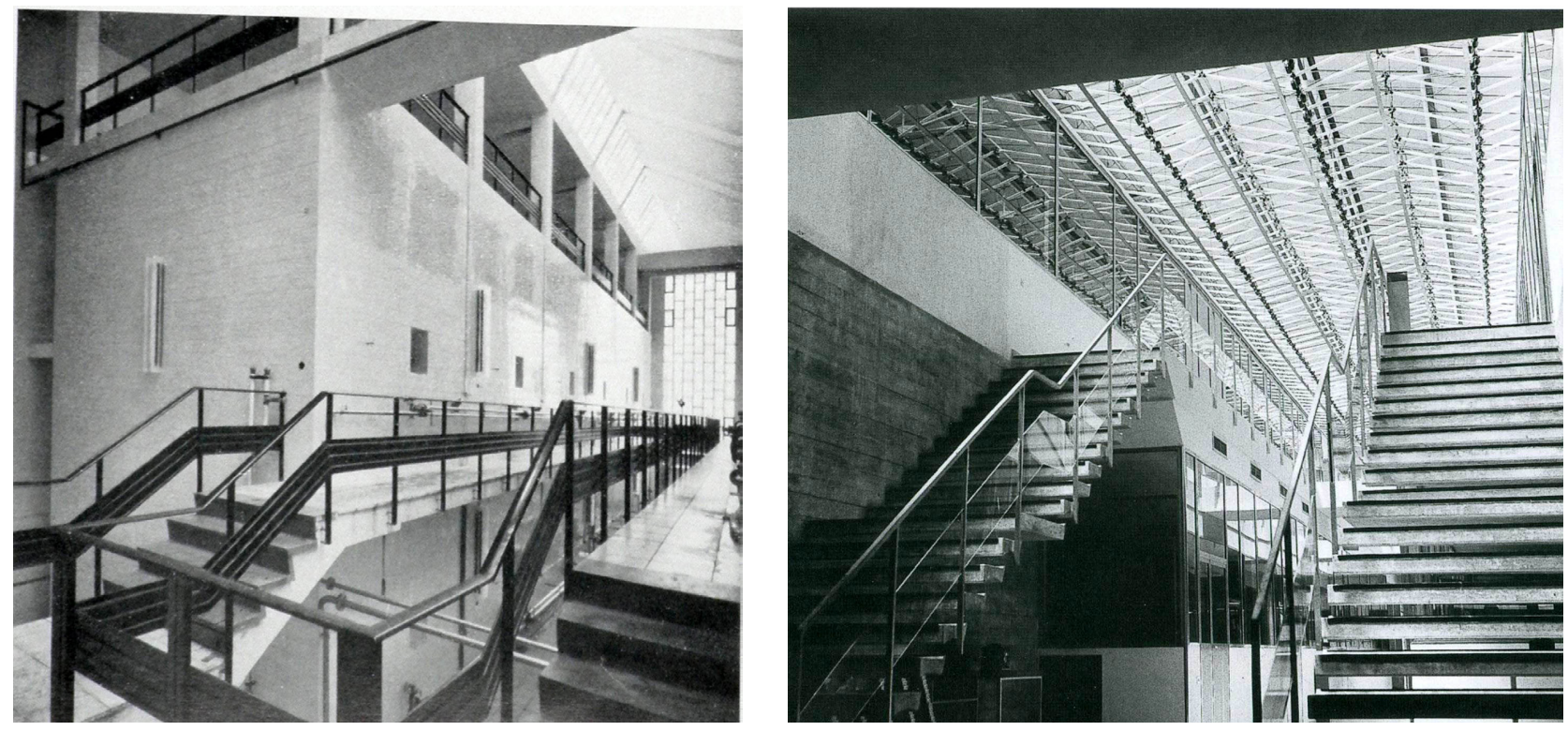

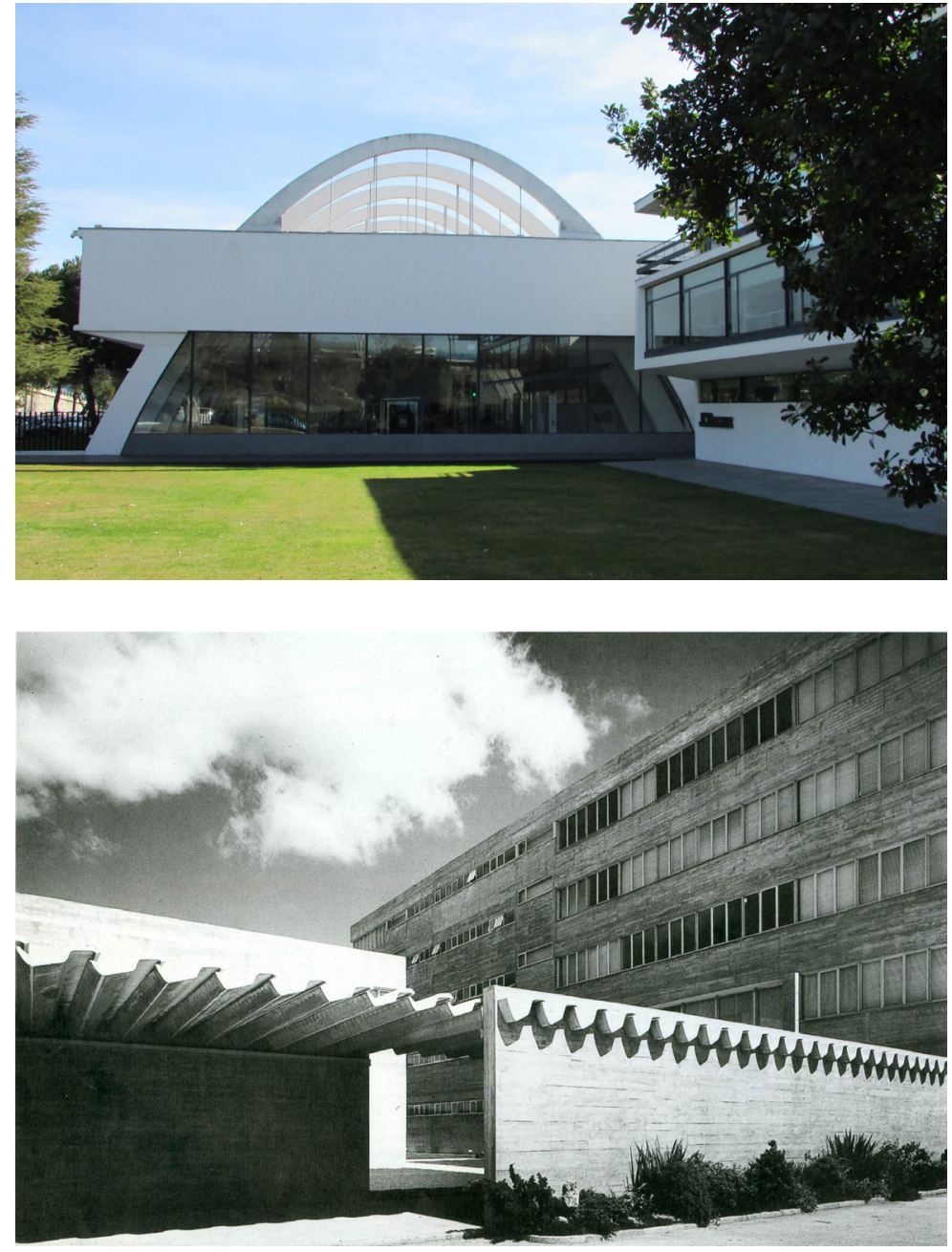

Figura 17. Fotografía actual de fachada con arcos parabólicos. Fotografía de la autora.

Figura 18. Detalle de marquesina. (Cánovas 1997: 132) para incorporar en un ámbito fabril y destinado a las máquinas, como es un edificio industrial, la dignidad de los espacios destinados al hombre. Ya anteriormente en los laboratorios Farmabión, había utilizado el vestíbulo para disponer una escalera casi escultórica, con un primer tramo rotundo de hormigón y otros dos tramos más ligeros a base de perfiles metálicos y peldaños de madera, junto con un pequeño estanque inundado de vegetación. En el edificio de oficinas de Made, el vestíbulo vuelve a ser protagonista al alojar en él una destacada escalera de hormigón con los peldaños volados y empotrados en los muros, de modo parecido a como lo hiciera Ferrater en su club Martini. Otro trato especial recibe la nave de fabricación donde dos escaleras paralelas ascienden a cada lado del patio central hacia el corredor de la planta superior, dotándolo de un halo casi místico a través de la luz cenital que ilumina dicho espacio (Figura 14).

\section{Luz cenital}

La iluminación cenital en la arquitectura industrial ha sido un tema recurrente a la hora de iluminar de manera homogénea un gran espacio de trabajo. En las dos obras comentadas la razón es otra.

En la nave de tinas, Jaime Ferrater no tuvo otra opción para iluminar este espacio que la luz cenital, ya que las paredes a ambos lados son ciegas al estar ocupadas por los depósitos de macerado del vermut, salvo parte del muro este en que colocó un panel vítreo en toda su extensión para reforzar el efecto luminoso. En esta nave, una galería a la que se accede por dos escaleras paralelas, con un patio central alargado, recorre la primera planta desde la que se accede a las tinas, resultando un espacio similar al que consiguiera Fisac en su obra de Made (Figura 15).

En el caso de este último, grandes ventanales continuos horizontales se abren a ambos lados de la nave de fabricación para proporcionar luz a las distintas dependencias distribuidas por las dos plantas. Sin embargo, el espacio central de distribución solo es posible iluminarlo desde arriba, con lo que resulta, junto con la sabia determinación de dividir las tabiquerías que dan al corredor con la parte superior acristalada, un acceso sumamente atractivo que invita a traspasarlo.

Ambas galerías de Ferrater y Fisac son los elementos espaciales interiores más llamativamente semejantes de los dos proyectos, siendo a la vez de gran originalidad dentro de la arquitectura industrial del momento (Figura 16).

\section{Novedad estructural}

La fábrica de Martini fue calificada en su momento de arquitectura vanguardista, e incluso "futurista" (Informes de la Construcción, 1965). La solución estructural de la nave de envasado dotó al conjunto de un carácter estético de gran valor plástico, elegante, sencillamente porque fue diseñada sin pretensiones, con la finalidad de ser útil con el mayor ahorro de material posible. Aún en la actualidad sigue cumpliendo su función y sigue irradiando vanguardismo y modernidad tras más de medio siglo (Figura 17).

En los Laboratorios Made, un elemento significativo marca la entrada al conjunto: la marquesina. Construida a base de hormigón armado, enfatiza y, a la vez, unifica los dos accesos de que dispone el conjunto. En la mayoria de sus obras, Miguel Fisac trata con sumo esmero los accesos a sus edificios, dotándolos, o bien de entradas abocinas, o de elegantes marquesinas, diseñadas con el fin de proteger de las inclemencias del tiempo a la vez que remarcan e indican el paso hacia el 
interior del edficio. Numerosos son los ejemplos en su trayectoria profesional, como en el edificio de oficinas de Seat en Barcelona, o los Laboratorios Farmacéuticos Farmabión de Madrid, ambos lamentablemente derribados, entre otros muchos.

El caso que ahora nos ocupa merece especial atención, ya que supuso la primera marquesina de piezas premoldeadas de hormigón armado tras varios años de investigación, precursoras de sus patentadas vigas-hueso, éstas de hormigón pretensado, ligeras, con capacidad para soportar grandes luces y, sobre todo, prefabricadas, objetivo que Fisac tuvo en mente desde sus primeros ensayos (Figura 18).

\section{El agua}

La idea recurrente de una lámina de agua entre pabellón de oficinas y fábrica aparece en los dos proyectos analizados, aunque Jaime Ferrater no pudiese llevarlo a cabo, ya que diseñó una piscina para el director de la fábrica cuya vivienda tenía previsto construir en la tercera planta del edificio de oficinas, vivienda que finalmente no se ejecutó. Sin embargo, no deja de resultar curioso que en la rehabilitación del conjunto fabril, obra de Carlos Ferrater Lambarri, ${ }^{4}$ se retome la idea y acabe materializándose, ubicando una lámina de agua en el mismo lugar donde Jaime Ferrater la imaginó (Figura 19).

En el caso de Miguel Fisac, el agua ha formado parte de alguno de sus proyectos fabriles, como es el caso de Farmabión, donde esa lámina la coloca en la cubierta plana del edificio, sobre baldosas de vidrio, para proteger de los rayos infrarrojos, y en el hall de entrada acompañando a una estudiada escalera y formando un pequeño jardín acuático. En Made, el cometido es el de refrescar un espacio entre el edificio de oficinas y la fábrica, junto a los dos accesos, diseñando una lámina de agua de planta rectangular entre vegetación, que sirva de alivio a la canícula estival (Figura 20).

\section{¿Arquitecturas perdidas?}

Este último punto se sitúa al margen de las anteriores coincidencias conceptuales que tanto Jaime Ferrater como Miguel Fisac desarrollaron en sus obras.

Cada día vemos desaparecer bajo los efectos de la piqueta alguno de los ejemplos de nuestro patrimonio industrial, cuyos edificios pasan a ser prescindibles en el momento en el que cesa la actividad para la que se proyectó, al margen de valores técnicos, históricos,
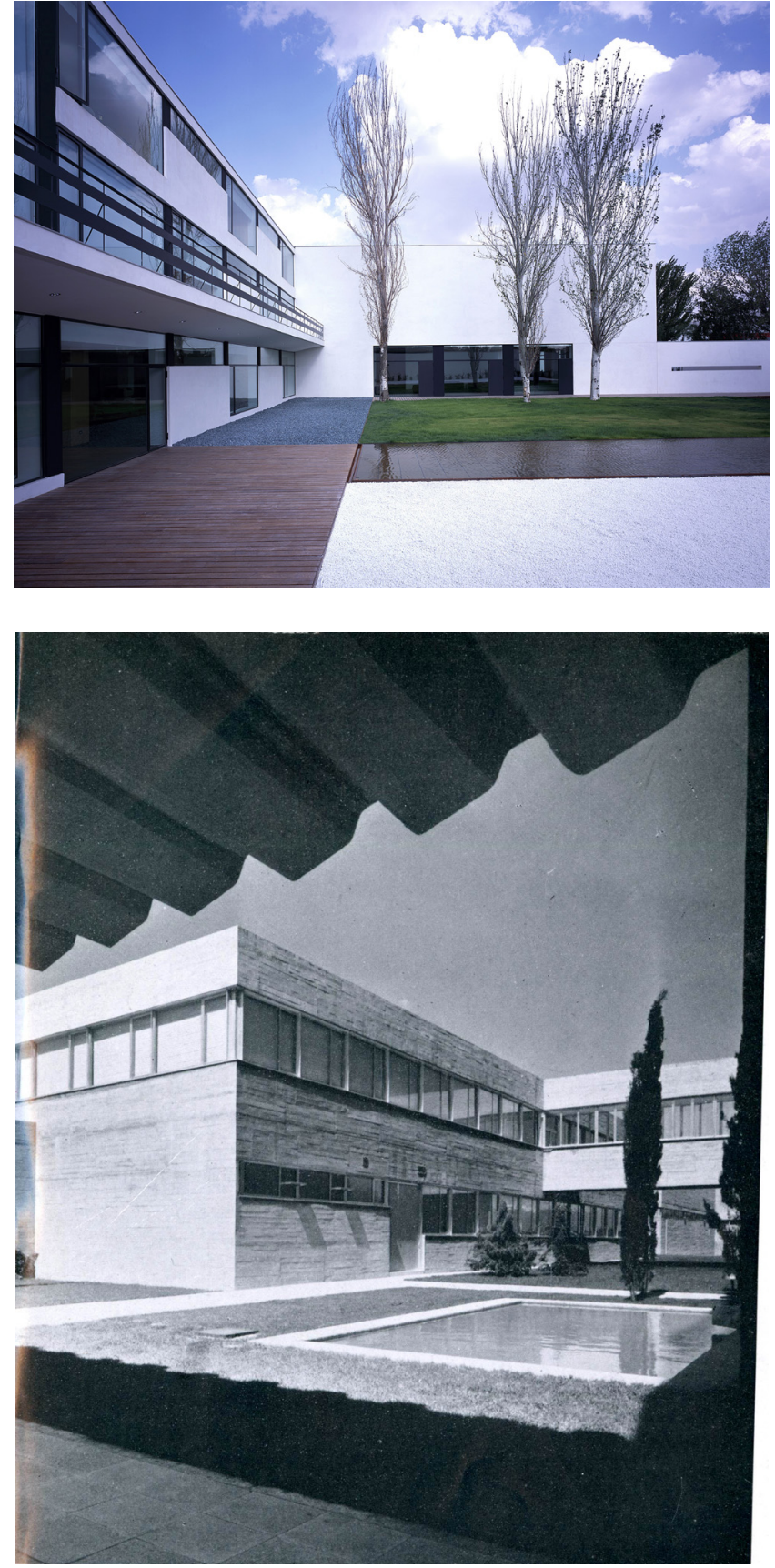

estéticos o morales. Aunque a veces celebremos la recuperación de los más afortunados inmuebles que han visto cómo recibían una segunda oportunidad.

Durante este medio siglo transcurrido desde su construcción, estas dos obras han cambiado de propietario. En el caso de la fábrica de Martini, ésta estuvo a punto de desaparecer al ser abandonada por la firma que le dio nombre. Afortunadamente, tras varios años en desuso y a pesar del deterioro que eso conlleva, fue rescatada para instalar en ella una empresa de soportes publicitarios. Sin embargo, este rescate no resultó gratuito. Con el fin de poder acondicionar el edificio a
Figura 19. Fotografia de la lámina de agua en jardin posterior de la actual sede de JC Decaux, anterior fábrica de Martini. Imagen cedida por Carlos Ferrater Lambarri.

Figura 20. Fotografia de lámina de agua entre el pabellón de oficinas y la nave de fabricación. Revista Hogar y Arquitectura, $\mathrm{n}^{\circ} 64$ Mayo-Junio, p.21. 


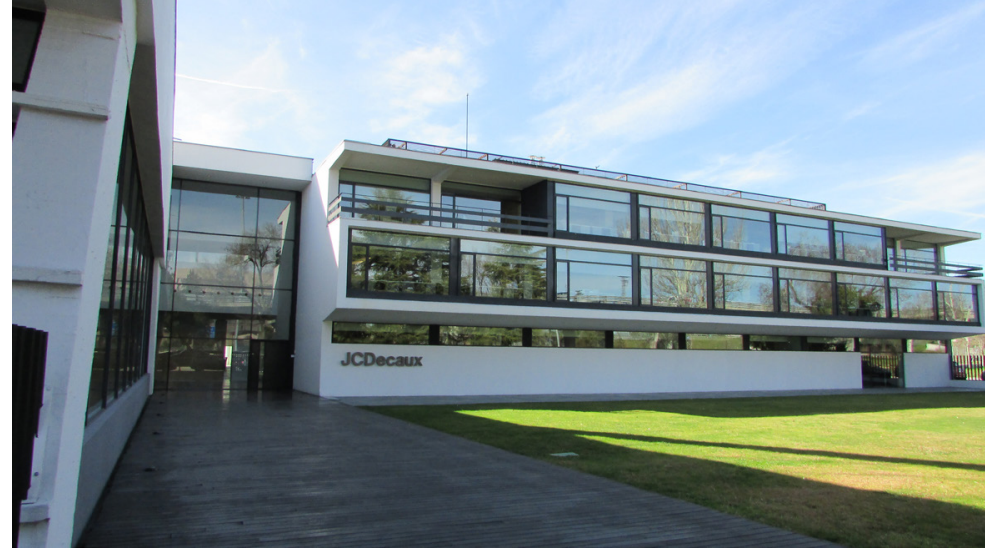

Figura 21. Fotografía de fachada de oficinas en el año 2015. Se aprecia el antiguo acceso al club Martini. Fotografía de la autora.

los nuevos usos y normativas, Carlos Ferrater Lambarri, coautor de la rehabilitación, tuvo que prescindir de lo que en su momento fue el club Martini, desapareciendo lamentablemente las escaleras aquí descritas, y clausurando su entrada. No obstante, los dos pabellones merecedores de un trato especial como era la nave de envasado y la de tinas, no han sufrido modificaciones importantes, por lo que podemos considerar que asistimos a una, en lineas generales, afortunada recuperación (Figura 21). ${ }^{5}$

En el caso de Made, el color propio del hormigón que Miguel Fisac quiso mantener inalterado como expresión de sinceridad con el material que sirvió de cerramiento exterior, fue modificado y pintado de blanco al cambiar la empresa farmacéutica inicial por los laboratorios Knoll. Años después una vez más cambió la empresa, adquiriendo el inmueble la farmacéutica Abbot, con lo que, para imprimir identidad, ésta determinó aplacar toda la fachada con un chapado de color blanco, ocultando así definitivamente el aspecto exterior por el que Fisac tanto abogó. Areán, Vaquero y Casariego, en su libro Madrid. Arquitecturas perdidas (1995) incluyeron los laboratorios Made como uno de aquellos elementos a calificar como perdidos por este motivo. Aún así, y en vista de la lamentable y total desaparición de otros edificios industriales de notable calidad, podemos alegrarnos de que esta singular obra siga en pie y conserve muchos de los elementos originales citados, como las escaleras, con su sutil luz cenital, el logrado hall de entrada al edificio de oficinas o la elegante y funcional marquesina, todos ellos muestras del ingenio y capacidad de uno de los grandes profesionales de aquellos años de reinicio de la modernidad.

Como breve reflexión sobre el futuro de este patrimonio industrial moderno tan vul- nerable, cabe decir que quizá su salvación podría pasar en parte por hacer algunas concesiones con el fin de adaptarlo a las necesidades de los tiempos actuales y así rescatar del olvido, o incluso de la total desaparición, a estos, en otro tiempo, contenedores de progreso y desarrollo, que en su día cumplieron con sobrada dignidad su cometido y que ya forman parte de nuestra historia. Sirvan de ejemplo estos dos destacados ejemplos.

\section{Notas}

1 Esta diferenciación es observable nitidamente al menos desde los complejos industriales diseñados por Albert Kahn en Estados Unidos en los años 30, en que un cuerpo simétrico representativo de oficinas se destacaba de las naves de talleres situadas detrás. Esta forma de composición fue repetida en multitud de ocasiones en sus proyectos industriales y constituyó un esquema estándar para lo industrial, ampliamente extendido en todo el mundo.

2 Se usa aquí una denominación impropia para un arco de hormigón. De los planos se deduce que es de tipo doblemente empotrado. Quizás el término proviene del conocido tipo de tres articulaciones, en el que al eliminar todas ellas, como es el caso, se sugiere que son sustituidas por tres empotramientos.

3 Algo similar había acontecido un par de años antes cuando, en 1956, el Instituto Nacional de la vivienda convoca un concurso de viviendas experimentales. En este concurso, Fisac hizo una propuesta industrializada para los cerramientos con las planchas Durisol, pero el jurado lo desestimó al considerarlo un material caro y, sobre todo, desconocido.

4 Entre ambos Ferrater existe una relación de parentesco: el padre de Carlos Ferrater Lambarri era primo hermano de Jaime Ferrater Ramoneda.

5 No obstante, en la nave de tinas se ha cubierto el espacio entre las dos pasarelas laterales con un forjado de chapa metálica y hay una nueva escalera en dicho espacio central que no estaba originalmente. No es conocido sin embargo si tales modificaciones estaban ya previamente a la reforma actual.

\section{Bibliografia}

Areán Fernández, Antonio, Vaquero Gómez, José Ángel y CASARIEGo CóRdobA, Juan. 1995. Madrid. Arquitecturas perdidas. 1927-1986. Madrid. Pronaos.

Arqués Soler, Francisco.1996. Miguel Fisac. Madrid. Pronaos.

AAVV. 2007.Arquitectura de Madrid, Periferia. Madrid. Fundación COAM.

AAVV. 1962. Bauen in Stahl 2. Construire en acier 2. Zürich, Verlag Schweizer Stahlbauverband.

AAVV.2007. Miguel Fisac. Huesos varios. Madrid. Fundación COAM. 
Cánovas, Andrés. 1997. Miguel Fisac. Medalla de Oro de la Arquitectura 1994. Madrid. Ministerio de Fomento y Consejo Superior de Arquitectos de España.

Del Río Lafuente, $M^{a}$ Isabel. 1984. Industria y Residencia en Villaverde. Génesis de un paisaje urbano en la periferia de Madrid. Madrid. Editorial de la Universidad Complutense.

AAVV. 1963. Fabrica para Martini Rossi-Canillejas. Arquitectura, $n^{\circ}$ 55, Julio, pp. 6-8. Colegio Oficial de Arquitectos de Madrid.

Echegaray Comba, G. y Barbero Rebolledo, M. 1953. Composición Arquitectónica: Instituto Técnico de la Construcción y el Cemento. Informes de la Construcción, $n^{\circ} 56$.

FisAC, Miguel. 1966. Laboratorios Farmacéuticos Made (Madrid). Hogar y Arquitectura, $n^{\circ} 64 \mathrm{Ma}$ yo-Junio, pp. 17-21. Ediciones y Publicaciones Populares.

FisAc, M. 1967. Laboratorios Farmacéuticos Made (Madrid). Baumeister, pp. 712-713.

García Braña, Celestino, Landrove, Susana, TostoES, Ana. 2005. Fábrica para Martini Rossi. La Arquitectura de la Industria 1925-1965. Barcelona. Fundación Docomomo Ibérico, p.208.

Giedion, Siegfried. 1978. La mecanización toma el mando. Barcelona. Editorial Gustavo Gili. Título original: Mechanization Takes Command. A Contribution to Anonymous History. Oxford. Oxford University Press, 1948.

AAVV. 1983. Guía de Arquitectura y Urbanismo. Tomo II. Madrid. Colegio Oficial de Arquitectos de Madrid.

AAVV. 2003. Laboratorios farmacéuticos Made. Madrid. AV Monografías, $n^{\circ} 101$, pp. 62-65.

AAVV. 1965. Martini \& Rossi - Madrid. Jaime de Ferrater Ramoneda, arquitecto. Madrid. Informes de la construcción, $\mathrm{n}^{\circ} 169$, pp. 35-45, Instituto Eduardo Torroja de la Construccción y del Cemento.

AAVV. 2001. Moderna y actualizada. Sede de J.C Decaux, Madrid. Arquitectura Viva, $n^{\circ}$ 142, pp. 142-145, Avisa.

AAVV. 2002. Sede de la multinacional Decaux en la antigua factoría Martini \& Rossi. XVI Premios: Urbanismo, Arquitectura y Obra Pública 2001, pp. 96-103, Ayuntamiento de Madrid, Gerencia Municipal de Urbanismo.

Sobrino, Julián. 1996. Arquitectura industrial en España, 1830-1990. Madrid. Ediciones Cátedra, S.A.

Archivos

Archivo Histórico del Colegio Oficial de Arquitectos de Madrid.

Archivo General de la Administración:

Proyecto de Fábrica de Martini y Rossi. Expediente $n^{\circ} 2027 / 1958$. Caja no 2.190 .

Proyecto de Laboratorios Farmacéuticos Made. Expediente $n^{\circ} 6027 / 1961$. Caja $n^{\circ} 3.813$.

Fecha final recepción artículos: 16/04/2018

Fecha aceptación: 07/06/2018

Artículo sometido a revisión por dos revisores independientes por el método doble ciego. 